\title{
Erratum to: Evaluation of toxicity risk of polycyclic aromatic hydrocarbons (PAHs) in crops rhizosphere of contaminated field with sequential extraction
}

\author{
Bin Ma • Huaihai Chen $\cdot$ Yan He $\cdot$ Haizhen Wang • \\ Jianming Xu
}

Received: 28 April 2010/Accepted: 3 May 2010/Published online: 26 May 2010

(C) Springer-Verlag 2010

\section{Erratum to: J Soils Sediments}

\section{DOI 10.1007/s11368-010-0212-8}

1. All "toxic equivalency", "toxicity equivalence", and "equivalency toxicity" in the text and figures should be changed into "toxicity equivalency".

2. Fig. 1 should be replaced by the following figure.

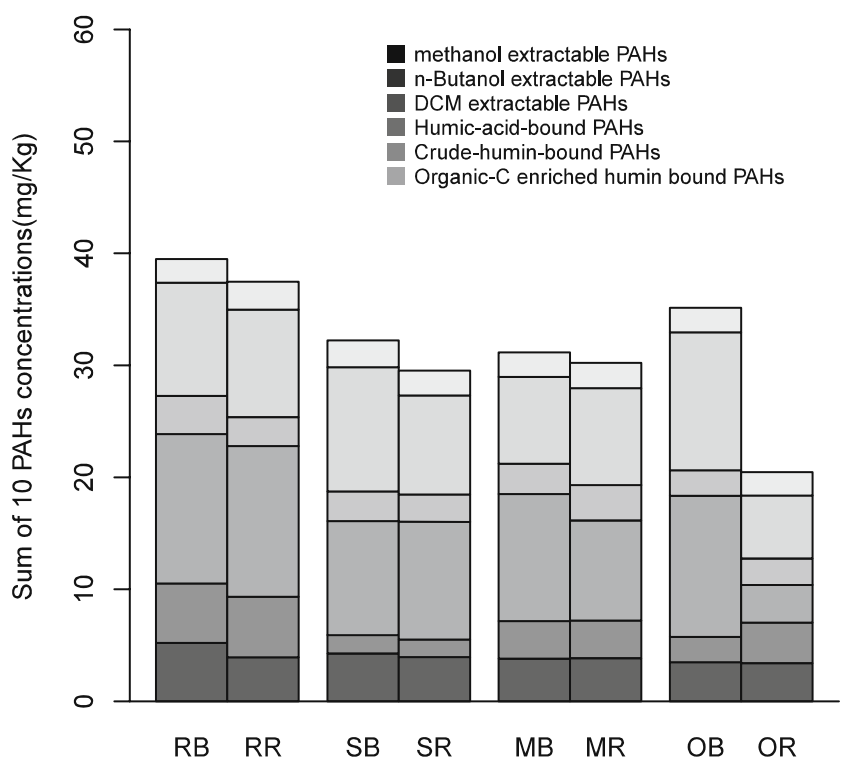

The online version of the original article can be found at http://dx.doi. org/10.1007/s11368-010-0212-8.

B. Ma $\cdot$ H. Chen $\cdot$ Y. He $\cdot$ H. Wang $\cdot$ J. Xu $(\bowtie)$

Zhejiang Provincial Key Laboratory of Subtropical Soil and Plant

Nutrition, College of Environment and Natural Resource

Sciences, Zhejiang University,

Hangzhou 310029, People's Republic of China

e-mail: jmxu@zju.edu.cn
3. Fig. 2 should be replaced by the following figure.

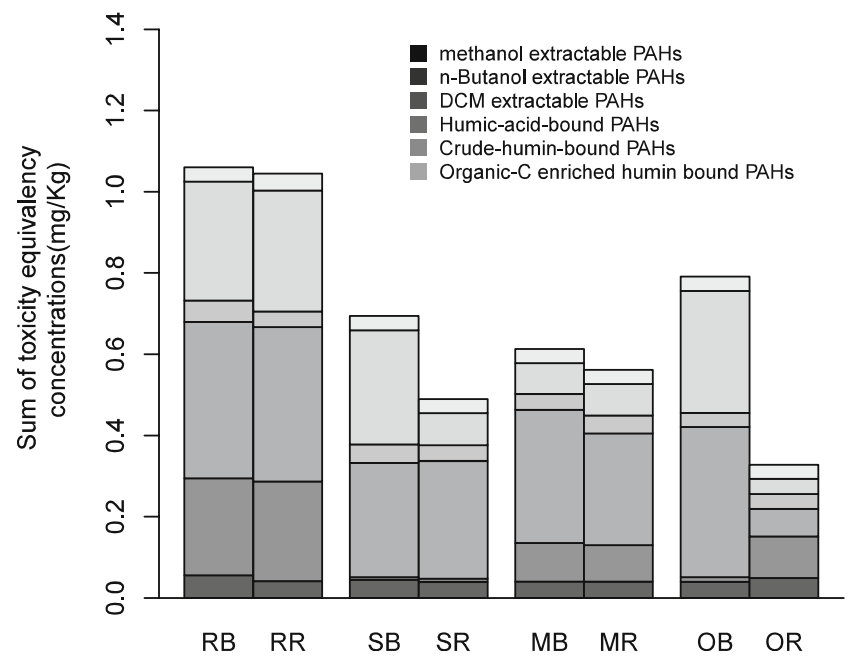

